\title{
Design of an engineered landfill as possible replacement for an existing dump at Akure, Nigeria
}

\author{
O.O. Ojuri ${ }^{1}$, T.O. Ajijola (1) ${ }^{1}$ and I. I. Akinwumi $\mathbb{C}^{2 *}$ \\ ${ }^{I}$ Department of Civil and Environmental Engineering, Federal University of Technology, Akure, Nigeria \\ ${ }^{2}$ Department of Civil Engineering, Covenant University, Ota, Nigeria \\ *Corresponding author Email: isaac.akinwumi@covenantuniversity.edu.ng
}

\begin{abstract}
This work focuses on the design of an engineered (semi-aerobic) landfill in Akure with a view to encourage a shift from the use of a dumpsite, which despite its adverse environmental impact has remained the method of waste disposal in Nigeria. Topographic maps, population figures, per capita waste generation and laboratory geotechnical investigation provided some of the basis for the landfill design. The waste generation potential of Akure and the leachate generation and gas emission potentials of the landfill were estimated. The cumulative waste generation potential of the landfill over its 15 years life was estimated to be $5.89 \times 10^{6} \mathrm{~m}^{3}\left(2.18 \times 10^{9} \mathrm{~kg}\right)$ and the landfill will require a dimension of $935 \mathrm{~m} \times 905 \mathrm{~m} \times 10 \mathrm{~m}$. The geotechnical tests revealed the proposed site will not yield under landfill loadings, while the hydraulic conductivity and consistency properties of the borrow pit soil samples show that they are suitable for use as liner materials. The design is composed of specifications for a liner, a capping system, leachate collection using a high-density polyethylene (HDPE) pipe system, gas capture and monitoring systems against leachate and landfill gas migration from the landfill. This research work will form readily accessible reference material for the design of engineered landfill in developing countries.
\end{abstract}

Keywords: landfill gas, leachate, liner, waste disposal, waste management

\section{Introduction}

Waste generation is an inevitable part of human nature. The rate of population growth and urbanization, over the years, has been alarming. This is responsible for the generation of very large quantities of municipal solid waste (Sujatha 2013). Due to the absence of a coherent strategy on waste management, it is common to find piles of indiscriminately disposed of waste and illegal dumpsites along major roads and at street corners in cities and urban areas of some developing countries. Several research works have identified links between poor waste management and poor condition of public health and the environment (Guerrero, Maas, and Hogland 2013; Oteng-Ababio, Arguello, and Gabbay 2013).

The anaerobic decomposition of municipal solid waste (MSW) leads to the generation of greenhouse gases, including carbon dioxide and methane, which contribute to climate change. Also, the decomposition of wastes results in the generation of leachate (often containing heavy metals, synthetic organic compounds), which can lead to contamination of ground or surface water. Open dumping typically leads to open burning, causing air pollution, animal (disease vector) infestation, and waste dispersion due to the actions of wind and scavengers.

Comparative studies of the various possible means of eliminating solid urban waste (such as landfilling, incineration, composting) have shown that the cheapest, in term of exploitation and capital costs, is landfilling (Renou et al. 2008). Although newer advances in disposal methods, such as pyrolysis, biodegradable containers and biodegradation have proven to have fewer functional problems, more feasibility problems in terms of initial and maintenance costs have been their drawback (Nwigwe 2008). The use of landfill is popular due to its versatility and simplicity in terms of technical requirements, environmental friendliness and socio-economic prospects (Malek and Shaaban 2008). In some developed countries, landfill method in the form of sanitary landfills with well-engineered facilities (liners, leachate collection and treatment systems, and a gas collection system) have been used to ensure the protection of public health and the environment (Aderemi and Falade 2012). In Japan, the semi-aerobic landfill is advanced (Ministry of Environment (MOE) 2012). In the semi-aerobic landfill, the leachate collection pipe drains leachate out of the landfill and also allows the aeration of the waste by heat convection resulting from differences between the inner temperature and outside air temperature (Shimaoka, Matsufuji, and Hanashima 2000). The expanded aerobic atmosphere, as a result, ensures early stabilization of waste, while also preventing the generation of methane and greenhouse gases (a known cause of global warming) (MOE 2012).

Despite advances in waste disposal methods in developed climes, open dumping even with its associating defects has remained the major practice in Nigeria (Ajijola 2016). Although quite a number of works have been carried out on waste management in Nigeria (Afolabi et al. 2018; Akinwumi et al. 2018; Oyekale and Oyekale 2017), many focused on waste collection and the impact of poor waste disposal on the environment. Also, a number of states in the country, including Lagos and Ondo, have in place a fairly workable waste collection system. However, very little has been done in the area of waste disposal as evidenced by the indiscriminately sited and unplanned open dumps. It is worthy of note that there is no functional engineered landfill in Nigeria. This work thus focused on delivering a design for an engineered landfill (semi-aerobic) for Akure the capital of Ondo State and its environs with a view of encouraging a safe and better waste disposal system, while also leading the way for more work in the area of waste disposal in Nigeria and other developing countries. 